\title{
Um corte radical no tecido da História: o livre uso do passado na narrativa biográfica de Paulo Leminski*
}

\author{
A Radical Cut in the Fabric of History: the Free Use of the Past in the \\ Biographical Narrative of Paulo Leminski
}

\author{
Everton de Oliveira Moraes \\ evermoraes@hotmail.com \\ Doutorando \\ Universidade Federal do Paraná \\ Rua Nilo Cairo, 176/92 - Centro \\ 80060-050 - Curitiba - PR \\ Brasil
}

\begin{abstract}
Resumo
Este texto tem como objetivo analisar os usos do passado na literatura biográfica de Paulo Leminski, bem como a ideia de historicidade que estes usos pressupõem. Tomar-se-á, para isto, como exemplo, a biografia do poeta catarinense Cruz e Sousa escrita pelo autor curitibano. Interessa perceber como Leminski busca criar uma narrativa literária que se utiliza de fragmentos de passado para problematizar a sua atualidade, tecendo, através desta narrativa, conexões com múltiplas temporalidades, questionando as relações entre sujeito e objeto, tais como elas se efetuam nos saberes disciplinares modernos e na política contemporânea. Esse tipo de experiência do pensamento pode ajudar a problematizar os limites de nossa imaginação historiográfica.
\end{abstract}

\section{Palavras-chave}

Paulo Leminski; Biografia; Historicidade.

\begin{abstract}
The aim of this text is to analyze the uses of the past in the biographical literature of Paulo Leminski and the idea of historicity that these uses presuppose. Its object is the biography of poet Cruz e Sousa written by Leminski. In the book, Leminski seeks to create a literary narrative that uses fragments of the past to problematize the contemporary situation, thereby establishing links with multiple temporalities and questioning the subject-object relations as they appear in modern disciplinary knowledge and contemporary politics. This thought-experiment can help us expand the limits of our historiographical imagination.
\end{abstract}

\section{Keywords}

Paulo Leminski; Biography; Historicity.

Recebido em: 24/4/2014

Aprovado em: 14/11/2014

\footnotetext{
*Esta pesquisa conta com financiamento da CAPES. Agradeço a leitura atenta de Pamela Fabris, Clóvis Gruner, Ernesto Marczal e Jones Custódio.
} 
Entre 1983 e 1985, o poeta curitibano Paulo Leminski ${ }^{1}$ escreve quatro biografias (Cruz e Sousa, Matsuó Bashô, Jesus e Trótski), inicialmente publicadas separadamente e depois reunidas post-mortem em um único volume, seguindo assim o desejo do próprio autor. Esses textos são destinados a homenagear vidas que Alice Ruiz, interpretando um depoimento do próprio Leminski, afirma se tratarem de "sobrevidas". Como se os seus gestos fossem dotados de uma potência que permanece atuando muito tempo depois de sua vida biológica ter findado, e que poderia servir como "parâmetro de uma outra vida", isto é, como "exemplos de radicalidade" capazes de inspirar a própria vida e as lutas do presente (RUIZ apud LEMINSKI 1998b, p. 9).

Para Leminski, essas vidas podem ser consideradas, de algum modo, relevantes para a sua atualidade. É que por mais que esses acontecimentos estivessem aparentemente confinados em um passado distante, Leminski acreditava que eles ainda agitavam as estruturas do presente, mesmo que a partir de seus subterrâneos e interstícios. E seria preciso articular uma narrativa que fosse capaz de lançar luz sobre essa obscuridade subterrânea.

E Leminski o afirma quando enxerga em cada um de seus quatro biografados os signos de uma vida guerreira que luta contra os imperativos de seu tempo e sobrevive a ele: em Cruz e Sousa, um simbolismo subversivo que teria aberto caminho para uma série de experimentações modernas; a sobrevivência dos haicais de Bashô nos interstícios da modernidade ocidental; a mensagem de Jesus, que também teria persistido aos inúmeros conflitos históricos nos quais esteve envolvida; e Trótski, que mesmo estando longe de uma atitude contemplativa, fez do sofrimento diante das diversas formas de opressão a matéria-prima de uma atitude revolucionária que abria novas possibilidades de pensar a revolução (LEMINSKI 1998b, p. 7).

São quatro textos escritos em formas que não as das biografias tradicionais. Não se encontram neles cronologias, origens ou trajetórias detalhadas e lineares. Leminski produz textos híbridos, com poéticas entrecruzadas. Apesar de ser um gênero em que se convencionou usar a prosa como fórmula de narração, as suas biografias apelam para recursos que fazem parte do repertório da poesia em verso. Para além do relato de vidas, tratam-se também de escritos literários, compostos a partir de pretensões estéticas e críticas, e que não cessam de problematizar as formas a partir das quais são escritos. Não são, portanto, textos apartados da dinâmica de suas composições poético-literárias.

No momento em que Leminski escreveu suas biografias, estas voltavam, pouco a pouco, a ser objeto de interesse dos historiadores, após um longo período de rejeição. E se durante esse período se privilegiou a longa duração, as estruturações que não se deixam compreender no espaço de tempo de uma vida individual, a questão que se colocava com o retorno da biografia era a de saber se tratava-se de tomar a história de um indivíduo "como um modo possível de

\footnotetext{
${ }_{1}$ Paulo Leminski, artista curitibano, é especialmente conhecido por sua poesia e por seus romances experimentais, mas também por sua produção no campo da crítica literária, pelas biografias que escreveu e por outras experimentações, como a vídeo-poesia, por exemplo. Sua arte é profundamente inspirada pelo Concretismo e pela Tropicália.
} 
acesso a realidades mais abrangentes" (AVELAR 2011, p. 140) ou como um "deslocamento do olhar em direção às distintas possibilidades de reconstrução do eu" (AVELAR 2011, p. 140). No primeiro caso, a biografia era uma nova entrada para lugares já bem conhecidos; no segundo, uma possibilidade de repensar as unidades e coerências pré-estabelecidas, aludindo ao caráter fragmentário e lacunar das construções sociais. O debate que teve lugar na historiografia dos últimos trinta anos, mais do que escolher entre essas duas alternativas, tornou mais complexas as relações entre história e biografia. A partir dele, historiadores repensaram as questões da agência dos sujeitos, da inserção destes em grupos e instituições, do uso da narrativa e da imaginação na escrita da história, e da multiplicidade das construções identitárias, entre outras.

Este artigo parte da biografia de Cruz e Sousa (1983) para tentar perceber quais usos do passado se produzem na construção de suas narrativas biográficas, entendendo que tais biografias constituem um saber específico do tempo e da memória que se faz a partir de um trabalho sobre fragmentos do passado e da construção de uma narrativa a seu respeito, ainda que se trate de um saber marcado por "certa imprecisão metódica e uma equivocidade intencional" (VIVEIROS DE CASTRO 2010, p. 26, tradução nossa), ${ }^{2}$ ou seja, um saber com outros parâmetros de rigor, uma metodologia sem pretensões de cientificidade, e uma não objetividade calculada.

Não está em questão, no entanto, verificar se as biografias escritas por Leminski produzem um conhecimento válido ou se cumprem os requisitos das obras de historiografia acadêmica. Pretende-se analisar qual a ideia de historicidade e quais usos do passado a literatura biográfica do poeta curitibano leva a cabo. Esse tipo de experiência do pensamento pode ajudar a problematizar os limites de nossa imaginação historiográfica.

\section{As batalhas nunca são decisivas: a sobrevida do acontecimento}

Leminski não tem uma concepção de tempo fechada e monolítica. "O seu tempo é vivo, em permanente reinvenção" (MACIEL 2004, p. 171). No entanto, uma ideia que atravessa os diferentes momentos de suas formas de pensar o tempo é a que parece aproximá-lo filósofo Walter Benjamin, ${ }^{3}$ segundo a qual é preciso "abandonar a atitude tranquila, contemplativa ante o objeto (passado), para se tornar consciente da constelação crítica em que este mesmo fragmento do passado se posiciona em relação a este presente" (BENJAMIN 2012, p. 128). Ao invés de um passado descrito a partir de uma verossimilhança factual, Leminski parece adotar a sugestão benjaminiana e romper com esse lugar frio do historiador metódico (não apenas os historiadores novecentistas da "escola metódica", mas todos os que se limitam à busca pela verdade factual) nas suas narrativas, tomando como ponto de partida lugares "rasgados", precários,

\footnotetext{
${ }^{2}$ No original: "Cierta imprecisión metódica y de una equivocidad intencional".

${ }^{3}$ Leminski cita Benjamin em alguns ensaios publicados na imprensa no final da década de 1970 e início da década de 1980. Em um deles chega a se definir como um dos incentivadores da leitura do filósofo alemão (entre outros autores estrangeiros) no Brasil. "Há anos venho divulgando (e até traduzindo) autores como Maiakovski, Brecht, Walter Benjamin, Pierce" (LEMINSKI 1977, p. 6).
} 
cheios de "lascas" de passado (BUCK-MORSS 2002, p. 145), lugares em que este último fere o presente, porque emerge repentinamente trazendo de volta incômodos acontecimentos ou restos de algo que se acreditava estar morto.

Não conviria, portanto, rejeitar o passado em bloco, como propunha boa parte dos modernismos. Exemplar a esse respeito é a apropriação que Leminski faz dos simbolistas curitibanos: enquanto Dalton Trevisan queria bani-los do rol de artistas significativos para a arte paranaense, o poeta curitibano enxergava nos simbolistas uma espécie de "antecipadores" das vanguardas artísticas que introduziram na arte, de maneira intuitiva, o princípio da incerteza, segundo o qual "o observador, ao observar, perturba a coisa observada" (LEMINSKI 2012, p. 288), rompendo com o naturalismo. Ao valorizar um traço do simbolismo que uma parte significativa dos modernistas se recusava a considerar, Leminski sugere que ainda haveria uma potência nesse passado que poderia ser utilizada no presente, ainda que, para isso, não fosse necessário identificar-se plenamente com a poética simbolista. Não é o passado como um todo que Ihe interessa, mas uma potência que ele carregaria. Potência, esta, capaz de afetar ${ }^{4}$, sensibilizar, e que interessa revirar, retomar, explorar, apropriar em favor do presente.

Talvez tenha sido justamente essa atenção dada à poética simbolista que tenha chamado a atenção de Leminski para Cruz e Sousa. Na biografia do poeta catarinense, os simbolistas também aparecem como "os primeiros modernos" (LEMINSKI 1983, p. 54), aqueles que primeiro perceberam a impossibilidade de reduzir a imagem (ícone) às palavras, de objetivá-las através do discurso, mas que, mesmo assim, colocaram para si a tarefa de "programar o indeterminado" (LEMINSKI 1983, p. 56). O que aqui equivale a dizer que os poetas simbolistas se colocaram a tarefa de deformar a palavra, fazer do seu verbo algo afetado por aquilo de que falavam e que, segundo a lógica do discurso naturalista, deveria estar reduzido à condição de mero objeto.

Leminski, na biografia supracitada, adota uma poética que hibridiza formas de narrativa, recorre aos sofisticados recursos linguísticos de seu presente, mas também acolhe e se inspira na poética que atribui aos simbolistas. E isso é significativo para a compreensão de sua ideia de saber, porque implica em uma relação com a memória que é distinta daquela que é articulada nas biografias celebrativas. Não se encontra aqui aquela atitude que procura tomar o máximo de distância (exterioridade) possível de seu objeto para confiná-lo a um lugar circunscrito e analisá-lo objetivamente; nem aquela outra, que situa o objeto fora da história, para além dela, como se o biografado fosse um sujeito soberano, exterior aos acontecimentos que Ihe ocorrem e capaz de manipulá-los a seu bel-prazer.

Está em questão, para Leminski, esforçar-se para compreender um acontecimento do passado que, dotado de uma sobrevida, o afeta, desordena suas coordenadas, joga-o para fora de toda identidade. Trata-se de um acontecimento rebelde a qualquer temporalidade fechada sobre si mesma, que irrompe para incomodar o presente.

\footnotetext{
${ }^{4}$ Os conceitos de afeto e afecção aqui utilizados remetem a uma série de textos de Gilles Deleuze (DELEUZE 2011).
} 


\section{Tirar tudo que o som tem de dor: a paixão e o contraefeito}

Um traço em comum entre os biografados escolhidos por Leminski é que estes são apresentados como sujeitos excessivamente afetados pelo mundo em que vivem, de tal modo que parecem estar acometidos por certo esgotamento: um Jesus que mesmo diante de um mundo de pecado, dava a outra face para bater; Bashô, que troca a vida guerreira e ativa do Samurai pela vida contemplativa do haicai; Trótski, que diante do despotismo e do capitalismo, mesmo estando longe de uma atitude de contemplação, movido pela paixão revolucionária, faz escolhas diferentes daquelas feitas por Lênin, abrindo novas possibilidades de pensar a revolução; por fim, Cruz e Sousa, afetado pelo racismo, pela burocratização da vida, pela normatividade restritiva das convenções literárias de sua época, como se estivesse constantemente acometido por uma "dor" e uma tristeza. Uma condição que, no entanto, não contradiz absolutamente a "vida guerreira" que Leminski enxerga em cada um de seus biografados. É que a luta, para ele, se dá a partir do momento em que se é afetado por um poder.

Na biografia de Cruz e Sousa, ao comentar a historicidade das formas de tristeza, ${ }^{5}$ Leminski fala do sabisha, uma "condição de abatimento emocional diante das coisas e do fluxo dos eventos", uma tristeza voluntária daqueles que sabem que "nada dura e que tudo é [...] metamorfose" (LEMINSKI 1983, p. 13). Diante de um mundo repleto de forças transformadoras que não se pode controlar, da percepção de um enfraquecimento da vontade pessoal como forma de transformação das condições de existência, há um abatimento consentido e solitário de quem sabe que a potência não nasce de si, não pode ser produzida por essa vontade. Não se trata de simplesmente deixar-se levar pelo curso dos acontecimentos, mas ter a consciência de que, se não se pode mudá-los com o "querer", pode-se ao menos pegar carona na potência que eles carregam. Fazer da imobilidade da tristeza uma maneira de captar essas potências; ficar em silêncio, parado e, ao ser afetado, saber "aproveitar" as possibilidades que esse afeto traz consigo.

Sabisha é, também, um estado de interpenetração com todas as outras coisas. Uki-ga, "o eu-fluente", essa sensação mais constante do pai do haikai japonês, Bashô, o seu "estado comum de tristeza solitária" (LEMINSKI 1983, p. 13).

Em uma conferência apresentada em Curitiba, Leminski elabora uma definição do seu conceito de "paixão", entendida como a condição de "ser passivo de uma ação" (LEMINSKI 2009, p. 325-326) ou acontecimento, de sofrer a ação de outros sujeitos ou outras forças. Trata-se de uma experiência da sensibilidade que sofre e, ao sofrer, sinaliza um mal-estar na cultura (KEHL 2010, p. 3-4). A paixão seria, portanto, a experiência do acontecimento, bem como o "sofrer" que dela decorre, a condição de estar sujeito à ação de uma ou mais forças do mundo.

\footnotetext{
${ }^{5}$ Além do sabisha, conceito retirado do pensamento oriental, comenta também a melancolia, a partir de Baudelaire; o banzo, nome dado ao sentimento de tristeza dos negros escravizados com saudade de sua terra natal; e também o blue, a tristeza dos negros norte-americanos, traduzida musicalmente no blues.
} 
Leminski constrói sua narrativa a partir da figura poética que, logo no início do texto, anuncia reger a vida de seu biografado, isto é, "a ironia, que diz uma coisa querendo dizer o contrário" (LEMINSKI 1983, p. 9). Figura que Leminski associa à potência do acontecimento de linguagem de transformar, transfigurar a realidade. No texto, Cruz e Sousa aparece como um "acrobata da dor", alguém que, tendo sido submetido às mais variadas adversidades, assume a tarefa de dar forma poética à própria vida, transformar "sofrimento e carência" em "beleza e significado" (LEMINSKI 1983, p. 10). Comentando o poema "O assinalado", o biógrafo escreve:

O poeta como assinalado. O marcado (Caim?) por um sinal.

Sinal para ver mais longe. Mas para sofrer mais fundo.

A negritude como sinal total: visibilidade integral

(LEMINSKI 1983, p. 71).

Ele parece crer que a ironia seja a figura retórica mais adequada para a biografia, não porque ela seria a única capaz de dar conta de narrar a vida de Cruz e Sousa, mas porque ela permite incorporar e hibridizar outras figuras de linguagem. Longe de pretensões de objetividade, seu texto toma posição, explicita seus conceitos e opções retóricas. ${ }^{6} \mathrm{O}$ biógrafo deixa as marcas de sua construção textual ao longo de toda a narrativa, que nem por isso acaba por se tornar subjetivista. Talvez essa opção, na verdade, revele algo da afecção que seu "objeto" exercia sobre ele.

Portanto, pode-se pensar também que a paixão não se limite aos personagens leminskianos, mas esteja presente na própria escrita do poeta curitibano, em sua narrativa do passado, como um ethos, como modo de escrever que dá forma ao texto. Não se trata de buscar, dividir, sintetizar e classificar. O interesse pelo passado, por uma parte dele, começa por um incômodo, um afeto, um encontro. Seu produto final não serão classificações, mas imagens. Imagens de forças, conflitos e lutas constituintes de subjetividades. Seus personagens parecem sofrer a violência do mundo em que vivem e lutam incessantemente contra essas forças que Ihes agridem. Não obstante, possuem a estranha habilidade de, ao sofrer, transfigurar esse sofrimento em potência, experimentando os limites desse mundo. Mas, para além disso, o próprio Leminski é afetado pela potência dessas vidas levadas ao limite e intensifica essas forças em sua escrita, através de uma "tradução" sem a qual não seria possível tornar compreensível algo que até então era incompreensível, uma vez que não é traduzível através de simples palavras, de meras descrições ou de análises puramente racionais (LEMINSKI 2012, p. 364). Assim, o saber que Leminski põe em prática funciona como aquilo que ele chama de "contra-efeito", isto é, o efeito que age sobre a

\footnotetext{
${ }^{6}$ É grande a lista de textos críticos em que Leminski mostra não conceber as formas narrativas como determinadas em última instância pela necessidade de objetividade ou qualquer outro imperativo. Seria possível citar, notadamente uma série de artigos publicados na imprensa curitibana ao longo das décadas de 1970 e 1980, parte deles reunida em coletâneas como Ensaios e anseios crípticos, publicadas originalmente por pequenas editoras curitibanas, recentemente reeditadas. Nesses textos, Leminski trata a opção por uma ou outra narrativa como uma questão de poder (forma é poder), cada modo de narrar implicando certas consequências políticas, dependendo também do contexto em que se produzem.
} 
causa, a partir dela. O sujeito afetado, cortado por uma "lasca" de passado e que busca produzir saber a partir desse corte, trabalhando sobre ele. "Tirar tudo que o som tem de dor", fazer da narrativa o contraefeito da paixão.

Leminski lança um olhar sobre fragmentos de passado, reconhecendo que se pode fazê-lo não apenas para entender a relação desses fragmentos com o seu tempo, mas também para "descobrir neles o que têm de permanentemente novo" (LEMINSKI 2012, p. 360). O acontecimento pelo qual o resto emerge para incomodar e provocar um mal-estar específico ou uma suspensão violenta de um tempo presente que se acreditava ser um tecido liso, pleno de identidade.

Mais do que um imperativo objetivista, portanto, é o próprio fato de Leminski ser um sujeito afetado por seu "objeto" que orienta a forma como a narrativa é construída. O sujeito desse saber não é, pois, aquele sujeito soberano, senhor do conhecimento, analista científico que domina seu objeto impondo a ele a forma de um texto objetivo; ou a de um romance naturalista, "com sua compulsão acadêmica" (LEMINSKI 2012, p. 322-323) e sua obsessão por "refletir" a realidade. Não é mais possível tomar esse distanciamento quando se admite que o que se investiga não é um objeto distante no tempo ou no espaço (uma civilização morta, um regime político do passado ou uma cultura exótica), mas um encontro vivido e sentido pelo próprio sujeito do saber. Quando então afirma que a "perfeição só existe na integração/dissolução do sujeito no objeto" (LEMINSKI 1983, p. 76), o poeta curitibano parece apontar para a necessidade de evitar a "possessão do objeto pelo sujeito" (ESPOSITO 2006, p. 267), de questionar os limites constitutivos do sujeito, isto é, diminuí-lo ao máximo.

Sendo assim, não se trata de tomar o passado como objeto a ser explicado, entendido ou representado, mas de buscar nele os acontecimentos que podem afetar o presente. Não a tentativa de entender a lógica que orientava as práticas do passado sem que seus sujeitos a percebessem, mas a lógica que se produz nas próprias práticas. O livre uso, um contraefeito, pressupõe um saber que abra a atualidade para a potencialidade do passado, que seja capaz de transformar e ampliar a imaginação dos sujeitos no presente.

\section{Aproximações de um possível: a tradução}

A biografia de Cruz e Sousa começa com a transcrição de uma denúncia, feita por um funcionário do Setor de Pessoal da Estrada de Ferro Central do Brasil à diretoria da empresa. Nela o funcionário relata a apreensão de um poema escrito por Cruz e Sousa, provavelmente no horário de seu trabalho, como arquivista, e pede providências diante de tal infração. Logo após a transcrição, Leminski complementa, respondendo ao pedido do funcionário: "Este livro é uma providência" (LEMINSKI 1983, p. 8). E se ele se propõe a responder a tal pedido, afirmando que seu texto é uma tomada de providências, essa atitude indica algo a respeito do modo como escreve a biografia.

O encontro do poeta-biógrafo com os poemas ou os fragmentos e restos da vida de seu biografado é o acontecimento que o incita, o motiva, ou até o coage a investigar, a pesquisar e a escrever. Esse encontro é o "não saber" a partir do qual o saber pode ser produzido. Esse encontro faz emergir "conflitos" 
que, mais do que apaziguar, interessa enfrentar. Podem mesmo ser chamados de "sintomas", para usar o termo de Didi-Huberman: "um sintoma aparece, um sintoma sobrevém, interrompe o curso normal das coisas segundo uma lei - tão soberana quanto subterrânea - que resiste à observação banal. $\mathrm{O}$ que a imagem-sintoma interrompe não é outra coisa que o curso normal da representação" (DIDI-HUBERMAN 2011, p. 63-64). Encontros aparentemente banais podem tornar-se matérias-primas para uma investigação, por causa das forças que mobilizam. A exemplo da leitura do documento em que Cruz e Sousa é denunciado, que, como um "relâmpago" benjaminiano, ilumina o "instante de um perigo" e atina Leminski para a experiência de burocratização e disciplinarização da vida contra a qual o poeta catarinense se debateu. Experiência pela qual Leminski se sente afetado, e que perturba e desajusta sua identidade com o presente, uma vez que olhar para as "batalhas não decididas" (LEMINSKI 1992, p. 41) do passado pode permitir compreender diferentemente os combates do presente.

Tanto no passado quanto no presente, trata-se de um poder que tende a reduzir as vidas à sua produtividade disciplinar. A tentativa de entender essa experiência de um poder que busca se materializar nos corpos e o modo como esses corpos se esforçam por resistir e inventar espaços de criatividade leva à produção de um saber. Não se busca conhecer, nesse saber, a representação da angústia de Cruz e Sousa através de seus poemas, mas o acontecimento mesmo dos poemas como forma de resistência.

A narrativa de Leminski começa por esse acontecimento, por esse encontro entre o gesto artístico e o burocrático, entre a poesia e o relatório, entre o funcionário-artista e o funcionário ubuesco ${ }^{7}$ anônimo. E não se trata apenas de uma tentativa do poeta curitibano de criar uma imagem guerreira de Cruz e Sousa, mas também de construir uma imagem da história como conflito, isto é, como produto do enfrentamento de forças. Construção coerente, aliás, com um "cenário onde já não se debatem (apenas) formas, mas forças" (ANTELO 2008, p. 1), e não somente na teoria literária, à qual Leminski estava muito atento, mas também na historiografia e na filosofia, dentre outros saberes.

Nas palavras de Durval Muniz, "uma história começa por um acontecimento raro, que não está instalado na plenitude da razão, que é cercado de vazios e silêncios, que clama por explicação" (ALBUQUERQUE JR. 2004, p. 67-68). É a partir de pequenos acontecimentos poéticos, pequenos gestos de rebeldia, de combate, de lances de dados do acaso, que Leminski conta a vida de Cruz e Sousa. No caso citado, trata-se de um poema que dá origem a uma desordem localizada, que se espalha, se multiplica e vai gerar uma série de outras pequenas, mas intensas desordens: no gosto "refinado" das elites culturais do Brasil, na estética da "prosa medida e rimada" do Parnasianismo (LEMINSKI 1983, p. 74), nas mentalidades racistas, no excesso de pudor das práticas artísticas da época, nas confinantes separações entre classes sociais (LEMINSKI 1983, p. 18-21). 
Mas se a narrativa preza tanto essa ideia de acontecimento, como explicar a afirmação segundo a qual não interessava dar "nessas páginas, espaço maior à vida de Cruz do que o tempo que ela teve no espaço-tempo concedido aos animais deste terceiro planeta depois do sol" (LEMINSKI 1983, p. 37-38). Não se deve pensar que a constante preocupação leminskiana com a descrição dos lugares sociais dos tempos em que seus biografados viveram seja um indício de um confinamento dos acontecimentos desviantes ou das invenções dos "malditos" dentro de estruturas estáticas e condições predeterminantes. Em outras palavras, a descrição da situação histórica de Cruz e Sousa não compõe um quadro histórico detalhado, linear e realista. Afinal, só uma história feita de forças em constante conflito é que pode servir ao tipo de "recuperação" que Leminski propõe.

Mais que contextos, são antes campos de batalha que são descritos e analisados, lugares em que acontecem conflitos e nos quais são desferidos golpes, traçadas estratégias, articuladas táticas, deslocamentos e que por vezes são danificados ou até completamente destruídos pelos próprios conflitos. Esses lugares não apenas interferem no conflito (favorecem mais um ou outro dos oponentes), mas estão, portanto, à mercê daquilo que acontece nele. Os gestos não apenas são constituídos por um tempo e um espaço determinados, mas os constituem. Mais do que sujeitos plenamente constituídos, as biografias leminskianas abordam gestos e práticas, e é a partir destes que a organização do texto é construída. É só através do gesto rebelde de escrita da poesia que se 200 pode ver a disciplina de trabalho funcionando para coibir esse gesto; é por meio do gesto desafiador das divisões raciais que estas passam a ser apresentadas no texto; o gesto que passeia entre diversos gêneros deixa ver a coerção que as formas tradicionais e consagradas exerciam sobre Cruz e Sousa e outros poetas "rebeldes" da época.

Os poemas, documentos a partir dos quais se constrói a narrativa, não são tomados apenas por seu "conteúdo". Não se trata de visitá-los para verificar se neles é possível encontrar relatos de fatos realmente ocorridos ou de comportamentos verossímeis. O que está em jogo é analisar os próprios poemas enquanto acontecimentos históricos, que respondem a certas demandas, aparecem dentro de certas regularidades, ao mesmo tempo em que se insurgem contra as forças que o objetivam e produzem um espaço-tempo outro em relação ao cotidiano burocrático e normativo.

Esses poemas, mais do que reproduções de estruturas de ação determinadas ou reflexos de aspectos do mundo no qual vivia, são analisados como armas de luta, instrumentos por meio dos quais Cruz e Sousa se fazia presente nas questões que diziam respeito à sua vida. Primeiro porque o próprio ato de escrever do poeta catarinense é tomado por Leminski como algo que permite a ele ocupar um espaço que normalmente não era ocupado por negros em sua época, o da escrita; em segundo lugar, porque a forma como escreve é entendida como algo que se constitui em um modo de se relacionar consigo mesmo (como se Cruz e Sousa transformasse sua vida e suas angústias - ou as problematizasse - em poesia) e com os outros (de maneira combativa e desafiadora). 
Leminski dá às práticas um lugar que não é nem o do confinamento dentro de padrões de comportamento pré-definidos, nem o da soberania do gesto racional que não respeita qualquer regra. Assim, as práticas podem ser entendidas como acontecimentos e, no caso dos poemas de Cruz e Sousa, como "acontecimentos poéticos". Com o termo, pretende-se dar conta daquilo que Leminski entende como o caráter não reflexivo da arte. Para ele, mais do que refletir a realidade exterior, a arte mantém com ela "tensões dialéticas" (LEMINSKI 2012, p. 99). A poesia, portanto, não seria mero efeito de determinada realidade, mas também produziria efeitos nela. O poeta "pretende construir [...] aberturas, ciente de que mexer profundamente com os homens é mexer com os fundamentos materiais em que se dá a comunicação" (LEMINSKI 2012, p. 99).

Na narrativa leminskiana, as experiências do poeta catarinense aparecem, como foi dito acima, quase sempre marcadas por uma luta contra as adversidades de seu tempo e de sua geografia. Leminski afirma que "as figuras do conflito, do estraçalhamento e da contradição vão perseguir toda a vida do poeta. E naturalmente - determinar o curso de sua poesia" (LEMINSKI 1983, p. 23). Elas são marcadas pela imagem do "acrobata da dor", aquele que, mesmo em meio a dificuldades, enfrenta-as e as supera, isto é, consegue criar, apesar delas: "na poesia, na realização enquanto texto, Cruz e Sousa superou o dilaceramento entre os antagonismos de ser negro no Brasil (mão-de-obra) e dispor do mais sofisticado repertório branco de sua época (o 'Espírito')" (LEMINSKI 1983, p. 10). Um certo "apesar de tudo" (DIDI-HUBERMAN 2012, p. 83-84) atravessa todo o texto. Como se, apesar do racismo, do classismo, do preconceito de quem acreditava que o negro era uma "raça-mão-de-obra", que não poderia se apropriar do repertório erudito destinado à educação dos brancos, do conservadorismo dos críticos, do gosto restrito e pouco afeito à experimentação das elites, Cruz e Sousa tivesse conseguido fazer poesia, criar objetos poéticos inovadores (LEMINSKI 2012, p. 99), acontecimentos poéticos. Acontecimentos que podem ser associados ao Simbolismo, mas que também se devem a uma tomada de posição que o aproxima de uma marginalidade subversiva, irredutível a qualquer formula poética ou estilo consagrado.

Mais do que o personagem biografado, mais do que as formas literárias em que sua poesia se insere, são as lutas nas quais ele foi jogado pela vida que aparecem na biografia. O documento oficial apropriado por Leminski deixa de fazer parte da longa série de relatórios produzidos por empresas, instituições e governos para se tornar imagem de uma vida marcada pelo conflito. A partir dessa imagem, Leminski começa então a tecer uma série de narrativas do combate de Cruz e Sousa contra os imperativos de seu tempo.

Essa invenção da imagem de uma "vida guerreira" para narrar as experiências do poeta catarinense indica a opção por um procedimento "epistemológico" específico: a "tradução", conceito tomado de empréstimo a um leitor de Benjamin, Haroldo de Campos (LEMINSKI 2012, p. 364), especialmente a ideia de tradução da tradição. Para Leminski, assim como para esses autores, este conceito engloba o sentido convencional de tradução, mas vai além dele, para significar o ato de "tornar compreensível aquilo que até 
então era incompreensível" (LEMINSKI 2012, p. 364); "aumentar o território de legibilidade" de um determinado acontecimento, produzir novas possibilidades de leitura. Mas também "criar uma co-realidade de um original", isto é, inventar uma nova realidade que traduza para os sujeitos do presente o "ritmo", a "imagem" ou o "tom" (CAMPOS 1977, p. 2-3) de uma realidade passada. Articular uma "linguagem inflamada, que ultrapassa a vontade de ornamento para atingir às vezes a beleza agressiva", em que "a expressão ultrapassa o pensamento" (BACHELARD 1990, p. 33). Isso o biógrafo também descreve como "a forma mais radical de recuperação da informação" (LEMINSKI 2012, p. 365), que não se esquiva "da contínua sedimentação de estratos criativos" que a história impõe ao "original" (CAMPOS 1977, p. 2); "aproximações (contemporâneas) de um possível (passado), de uma série estocástica" (LEMINSKI 2012, p. 365), da qual os sujeitos da atualidade poderiam "saquear" armas para suas lutas.

\section{A imaginação como método: a montagem}

Sonhar, inventar, imaginar. Parecem ser traços constitutivos da "metodologia" de um saber dos sintomas, como se para lidar com os encontros e as contingências do acontecimento, fosse necessário usar a imaginação. A tradução leminskiana não almeja à fidelidade em relação ao significado do original, mas aposta na imaginação (ou "reimaginação", para falar como Haroldo de Campos), entendendo-a não como mero devaneio, criação mental desregrada, mas como atitude que tem seus procedimentos. "Uma via de

202 conhecimento, de acesso à realidade, tão (ou mais) poderosa do que a razão" (LEMINSKI 2012, p. 181), processo de criação e superposição de imagens, que trazem em um só golpe, juntos, o "ocorrido" e o "agora" (DINIZ 2009, p. 12), atual e inatual, com uma força capaz de abrir o presente a múltiplas temporalidades. Imaginar é, antes de tudo, brincar com as imagens desse choque entre passado e presente.

Leminski busca "traduzir" para o presente uma experiência vivenciada por Cruz e Sousa no passado. Não está em jogo, portanto, representar o passado da maneira mais objetiva possível, colocando-se como um narrador onisciente, mas inventar imagens do passado através da montagem de fragmentos deste e de outros tempos. O poeta curitibano parece, além disso, disposto a pagar o preço desse procedimento: a já comentada imprecisão metódica. Um custo que Ihe parece baixo, em vista dos ganhos que advêm da possibilidade de "aumentar o terreno da legibilidade" e com isso ampliar as possibilidades de liberdade na atualidade (LEMINSKI 2012, p. 364).

Assim, pode-se encontrar na biografia de Cruz e Sousa uma espécie de montagem de fragmentos de tempos heterogêneos que, através de epígrafes ou de citações textuais, tem a função ora de situar o poeta catarinense em relação à temporalidade histórica específica, ora de servir como analogia ou como forma de relacionar a poesia de Cruz e Sousa com outros tempos e espaços.

Não basta recuperar o passado por si mesmo, é preciso torná-lo potente para afetar o presente, para "exercer o papel de criação" (LEMINSKI 2012, p. 360) e, para isso, a montagem, a reorganização das imagens do passado, é 
o método capaz de dar conta da demanda de um livre uso, de um saque da tradição, dizendo o que nela interessa e o que não interessa para o presente. Recuperar para a atualidade as potências "malditas e minoritárias" do passado é inseri-las em uma "linhagem de radicalidades" (LEMINSKI 2012, p. 362), rearranjá-las em outra ordem de legibilidade. Um gesto que permite não apenas entender de outro modo o lugar que ocupam em sua própria temporalidade, mas perceber como essa linhagem de radicalidades pode fazer parte de uma política do presente, que busca abrir novas possibilidades para o futuro.

Capturadas por um discurso acadêmico que as apazigua, muitas vezes as vidas e suas poéticas precisam ser afrontadas novamente, e essa é a ideia da remontagem, que parece orientar o trabalho biográfico de Leminski. Construir uma nova legibilidade para esses poemas-documentos significa não se contentar com as leituras corriqueiras e lineares que delas são feitas por certa crítica literária ou história da literatura. "Será restituir, recontextualizar essas imagens numa montagem de outro gênero" (DIDI-HUBERMAN apud HONESKO 2011, p. 5).

Mais do que remeter as poéticas a um suposto solo de origem, Leminski se utiliza de referências anacrônicas e inusitadas. Como, por exemplo, a aparição de poemas de Caetano Veloso ou Haroldo de Campos, ao lado dos poemas de Cruz e Sousa. Essa montagem heteróclita parte de uma reminiscência ("como não lembrar de...") para sugerir não uma continuidade ou influência, mas uma sobrevivência, uma apropriação, como se os poetas contemporâneos tivessem, em seus poemas, sabido ocupar o espaço aberto a duras penas pela luta de Cruz e Sousa.

Além dessas referências, há também outras, com as quais Leminski vai construindo relações nada óbvias de analogia entre Cruz e Sousa e outros pensadores de diversos saberes. A título de exemplo, recolhem-se as seguintes passagens entre dezenas de outras no texto:

Ou como diz Van Gogh, numa carta, "expressar o físico pelo psíquico, em imagens e cores". Ou em sons e palavras, diríamos, Cruz e Souza conosco (LEMINSKI 1983, p. 46).

Isso, Freud, o maior dos expressionistas, seu contemporâneo [de Cruz e Sousa], afirma, ao criar uma técnica de cura baseada na expressão dos desejos recônditos (LEMINSKI 1983, p. 46).

Castro Alves fez retórica sobre a condição negra.

Cruz e Sousa era negro (LEMINSKI 1983, p. 70-71).

Como não lembrar este outro Concerto em A, nosso contemporâneo, a "Clara" de Caetano Veloso (LEMINSKI 1983, p. 50).

Essas analogias não têm um caráter explicativo, didático, mas a função de multiplicar os sentidos: ao invés de ler a poesia de Cruz e Sousa a partir de um paradigma lógico, como produto de uma geografia específica (região, nação, etnia, etc.) e de um tempo (época histórica, movimento ao qual está associado na história da literatura), entender as conexões do poeta com o mundo, com a alteridade e com a multitemporalidade que o atravessa, isto é, apostando no paradigma analógico do "como" (CAMPOS 2006, p. 247-265). Um poema vai 
sendo encadeado a outros poemas, textos e acontecimentos, a este "como", criando analogias, entendendo-se que uma poética não se relaciona apenas com sua contemporaneidade e com seus correlatos artísticos, mas com uma série de discursos e práticas dos mais distintos lugares e temporalidades.

Assim, o biógrafo procura dar conta desse "sujeito" complexo do qual fala, narrando a vida e a poesia de Cruz e Sousa como um agregado de temporalidades que envolvem o enfrentamento deste em relação ao racismo, à herança dos tempos de escravidão e à burocratização da vida cotidiana nas cidades, levada a cabo por todo um aparato modernizador. Mas também o contato com fragmentos da cultura erudita que envolvia inclusive boa parte da poesia europeia do século XIX, com nomes como Baudelaire, Mallarmé, Verlaine, Rimbaud, etc. Desse modo, os poemas de Cruz e Sousa seriam não apenas produto de seu "contexto" imediato, mas da multiplicidade de encontros com outras temporalidades (com obras, com pessoas, com imagens, poderes, etc.) que os constituem em seu presente e propiciam uma abertura ao futuro.

No ensaio $A$ tarefa do tradutor, Benjamin chama a atenção para a necessidade de submeter a língua do tradutor a um choque com a língua do original (BENJAMIN 2008, p. 80). Como se, para transcrever modos de dizer criados em uma língua estrangeira, fosse preciso escavar e moldar a língua nativa para forjar nela novos modos de dizer (CAMPOS 2006, p. 153-156). Sendo assim, mais do que abolir as diferenças entre as línguas em favor de uma pretensa fidelidade e unidade, a tradução seria uma prática que abre a língua do tradutor para a sua multiplicidade (GAGNEBIN 1994, p. 33). Ao transcrever um texto, o tradutor é forçado a "reimaginar" (CAMPOS 1984, p. 245) o texto original, rompendo as "barreiras apodrecidas" (BENJAMIN 2008, p. 79) de sua língua, abrindo-a para a possibilidade de dizer diferentemente. De igual modo, o que Leminski faz ao traduzir uma experiência passada para a sua atualidade é submeter esta última ao choque com aquilo que sobrevive da primeira, confrontando modos de historicidade, iluminando outras formas de viver o tempo, alargando as possibilidades de experiência, produzindo uma imagem capaz de abrir o presente à multiplicidade temporal que nele existe.

A montagem literária é, em Leminski, uma das possibilidades da tradução. Imaginar analogias, organizar citações, aproximar acontecimentos tidos como díspares, são formas de produzir sentidos, criar nexos onde até então eles pareciam insuspeitos. Eis uma das formas de alertar para as sobrevivências na atualidade de um passado que se acreditava estar morto. Talvez Leminski tenha seguido, neste ponto, a sugestão de Haroldo de Campos quando evocava a necessidade de uma "historiografia do como" (CAMPOS 2006, p. 247-248).

\section{Livre uso dos vestígios do passado}

Não se trata, portanto, de narrar um passado estático, que esperaria passivamente por uma revisitação, muito menos descrever o peso de uma tradição que paralisa a ação; mas de escrever a partir de fragmentos de passado que rasgam o tecido supostamente contínuo do tempo. Leminski encontra nos poemas de Cruz e Sousa essa potência de radicalidade com a qual busca 
"desatualizar" o presente. Quando reivindica a imaginação no lugar da verdade e da representação, não é uma forma de escapismo ou delírio inconsequente, mas uma forma de problematizar o modo como essas relações se dão, não apenas nos saberes, mas no cotidiano urbano que vivencia.

Talvez seja possível pensar que a poesia e o saber poético do tempo sejam, para Leminski, uma forma de problematizar os dispositivos de um utilitarismo que, para ele, representava um desejo "burguês" (mesmo que dissimulado) de submeter o tempo a certos "fins": seja aquele dos artistas e intelectuais engajados, para quem a passagem do tempo correspondia ao aperfeiçoamento da consciência de si ou de um "povo", rumo à sua libertação frente a uma elite "colonial"; seja um certo academicismo, que reduzia o tempo passado a uma objetividade, dando-Ihe um lugar bem delimitado, nos confins de um "não mais", domesticando-o por meio de uma disciplinarização; seja, enfim, o utilitarismo do mercado, no qual o "passado" era recuperado como objeto de consumo através de livros, modas, telenovelas, etc. Essas formas "burguesas" de apropriação do passado, segundo ele, almejavam separar as pessoas da possibilidade de "cortar o tecido da história" (LEMINSKI 2012, p. 362) para buscar o que Ihes interessa "no processo vivo de uma tradição" (LEMINSKI 2012, p. 362). Como se, ao postular a "exemplaridade", a objetividade ou a lucratividade do passado, engajados, acadêmicos eruditos e "empresários" deixassem ver a cumplicidade insuspeita que havia entre eles, apesar de seu aparente antagonismo. Nos três casos, tratar-se-ia de neutralizar a força do passado para torná-lo objeto de imitação, de culto ou de consumo.

Na biografia, Leminski não se apresenta como sujeito de conhecimento que domina a realidade que descreve, transmitindo seu saber ao leitor. Ao contrário, faz da própria escrita do texto um processo de subjetivação. Escrita esta que é entendida como acontecimento que se dá no choque de um ser vivo com os dispositivos, com a linguagem (AGAMBEN 2007, p. 55-63). Tanto em Leminski quanto em Cruz e Sousa, não há um sujeito com sua ideologia, mas textos / poéticas nos quais os escreventes jogam sua própria existência, uma experiência da qual não saem os mesmos, lugar da construção de mitos e imaginários, mas também da experiência poética da loucura (LEMINSKI 1983, p. 71) e da "dissolução do sujeito no objeto" (LEMINSKI 1983, p. 76). A escrita não é tanto a ação pela qual uma subjetividade se expressa, com sua ideologia, seu imaginário ou seu inconsciente, nem onde se revela o pensamento de "seu tempo", mas um acontecimento por meio do qual se produzem e se desfazem subjetividades, em que seres vivos encontram a linguagem e exibem nela, em um gesto, sua irredutibilidade a ela (AGAMBEN 2007, p. 63).

Ao questionar a tradicional relação sujeito-objeto e praticar uma metodologia da montagem e da tradução, Leminski busca se esquivar desses imperativos utilitaristas que percebe na cultura ocidental. Sua escrita biográfica, enquanto liberação do referencial e experimentação inutilitária da linguagem e da memória, deveria arrancá-las dessa "colonização" levada a termo pelo "mercado", pela academia, pelo mundo da arte, pela política institucional, restituindo-a ao uso comum (AGAMBEN 2007, p. 79) e às suas inúmeras possibilidades: 
A ditadura da utilidade, $[\ldots]$ o princípio da utilidade corrompe todos os setores da vida, nos fazendo crer que a própria vida tem que dar lucro. O lucro da poesia quando verdadeira é o surgimento de novos objetos no mundo. Objetos que signifiquem a capacidade da gente de produzir mundos novos. Uma capacidade in-útil. Além da utilidade. Existe uma política na poesia que não se confunde com a política que vai na cabeça dos políticos. Uma política mais complexa, mais rarefeita, uma luz política ultravioleta ou infravermelha. Uma política profunda, que é crítica da própria política, enquanto modo limitado de ver a própria vida (LEMINSKI 1997, p. 77-78).

Leminski esboça, portanto, um saber que mais do que buscar reconstituir uma realidade passada por meio do texto, funciona criando formas de se relacionar com outras instâncias da realidade. Não apenas se faz o movimento que vai dos vestígios do passado à sua representação fiel em uma narrativa, mas também se considera que as relações entre linguagem e realidade são múltiplas, bem como suas formas de tradução e figuração. E, para ele, apenas longe do desejo de representação naturalista é possível pensar um livre uso do passado, dos acontecimentos que sobrevivem ao seu tempo "original". Exemplos desse livre uso poderiam ser encontrados nos pensadores da modernidade em sua relação com o imaginário grego: Marx e seu "impulso prometeico", Nietzsche e sua "alma dionisíaco-apolínea" e Freud com o Édipo e o narcisismo (LEMINSKI 1998a, p. 63-64): cada um, a seu modo, teria sabido se apropriar da potência do passado para criticar e desestabilizar o seu presente.

Esses pensadores souberam se utilizar do passado, de fragmentos dele 206 sem, no entanto, reduzi-los a mero produto subjetivo do sujeito do saber ou a elementos que permitiriam construir certa verossimilhança com relação a uma realidade passada. E é essa experiência da invenção de múltiplas e tensionadas formas de relação com as presenças do passado na atualidade que caracteriza a historicidade leminskiana. A tradução, por sua vez, é o modo como Leminski articula essas presenças em suas narrativas.

Trata-se, nessas biografias literárias, de pensar um livre uso do passado, contra toda exemplaridade, objetividade e lucratividade. Para usar a expressão de Walter Benjamin, está em questão saquear a tradição, ir ao passado para buscar armas para as lutas políticas do presente, mas também fazer da própria tradução desse passado uma arma. "Recuperar" as "invenções" dos "malditos e minoritários", reconstituindo uma "linhagem de radicalidades" (LEMINSKI 2012, p. 365-366) que pode funcionar como inspiração para uma atitude radical no presente. Mas, também, rasgar o "tecido da história" (LEMINSKI 2012, p. 362) deixando ver o emaranhado de tempos que se agitam sob a superfície aparentemente lisa e contínua do presente.

\section{Referências bibliográficas}

AGAMBEN, Giorgio. Profanações. São Paulo: Boitempo, 2007.

ALBUQUERQUE JR, Durval Muniz de. No castelo da história só há processos e metamorfoses, sem veredicto final. In:

História: a arte de inventar o passado. Bauru, SP: Edusc, 2007, p. 67-84. 
ANTELO. Raúl. As imagens como força. Revista Crítica Cultural, v. 3, n. 2, p. 1-8, 2008.

AVELAR, Alexandre de Sá. Figurações da escrita biográfica. ArtCultura, Uberlândia, v. 13, n. 22, p. 137-155, 2011.

BACHELARD, Gaston. Fragmentos de uma poética do fogo. Brasiliense: São Paulo, 1990.

BENJAMIN, Walter. A tarefa do tradutor. In: CASTELLO BRANCO, Lucia. A tarefa do tradutor, de Walter Benjamin: quatro traduções para o português. Belo Horizonte: Fale/UFMG, 2008, p. 66-81.

O anjo da história. Belo Horizonte: Autêntica, 2012.

BUCK-MORSS, Susan. Dialética do olhar: Walter Benjamin e o projeto das passagens. Chapecó: Argos, 2002.

CAMPOS, Haroldo de. Da tradução como criação e como crítica. Diário do Paraná. 10 mai. 1977, p. 2-4.

Metalinguagem e outras metas: ensaios de teoria e crítica literária.

São Paulo: Perspectiva, 2006.

- Tradução, ideologia e História. Remate de males: território da tradução, n. 4, p. 239-247, 1984.

DELEUZE, Gilles. Crítica e clínica. São Paulo: Ed. 34, 2011.

DIDI-HUBERMAN, Georges. Ante el tiempo: historia del arte y anacronismo de las imágines. Buenos Aires: Adriana Hidalgo Editora, 2011.

Diante da imagem: questão colocada aos fins de uma história da arte. São Paulo: Editora 34, 2013.

Imagens apesar de tudo. Lisboa: KKYM, 2012.

DINIZ, Davidson de Oliveira. Walter Benjamin e as passagens: uma narratividade poética do histórico. Cadernos benjaminianos, v. 1, n. 1, p. 1-20, 2009. ESPOSITO, Roberto. Categorias de lo impolítico. Buenos Aires: Katz, 2006.

GAGNEBIN, Jeanne Marie. História e narração em Walter Benjamin. São Paulo: Perspectiva / Fapesp; Campinas: Editora da Unicamp, 1994.

HONESKO, Vinicius. Mãos ao alto: olhos armados. Sopro: panfleto políticocultural, n. 56, p. 2-10, 2011.

$\mathrm{KEHL}$, Maria Rita. A melancolia em Walter Benjamin e em Freud. In: Anais do III Seminario Internacional Políticas de la Memoria "Recordando a Walter Benjamin: Justicia, Historia y Verdad. Escrituras de la Memoria", Buenos Aires, Argentina, 2010, p. 1-12.

LEMINSKI, Paulo. Cruz e Sousa: o negro branco. São Paulo: Brasiliense, 1983. Ensaios e anseios crípticos. Curitiba: Polo Editorial do Paraná, 1997. Ensaios e anseios crípticos. 2a ed. ampliada. São Paulo: Unicamp, 2012. 
. Metaformose: uma viagem pelo imaginário grego. São Paulo: Iluminuras, 1998a.

Vida: Cruz e Sousa, Bashô, Jesus e Trótski. Porto Alegre: Sulina, 1998b. . Poesia: paixão da linguagem. In: NOVAES, Adauto (Org.). Os sentidos da paixão. São Paulo: Companhia das Letras, 2009, p. 322-350.

. Uma carta uma brasa através: cartas a Régis Bonvicino (19761981). São Paulo: Iluminuras, 1992.

MACIEL, Maria Ester. Nos ritmos da matéria: notas sobre as hibridações poéticas de Paulo Leminski. In: DICK, André; CALIXTO, Fabiano. A linha que nunca termina: Pensando Paulo Leminski. Rio de Janeiro: Lamparina, 2004, p. 171-179.

PEDROSA, Celia. Paulo Leminski: Sinais de vida e sobrevida. Alea: Estudos Neolatinos (Impresso), v. 8, n. 1, p. 55-74, 2006.

VIVEIROS DE CASTRO, Eduardo. Metafísicas caníbales: líneas de antropología postestructural. Buenos Aires: Katz, 2009. 